\title{
Skleroderma olgularında ellerde oluşan kronik terminal falanks patolojilerinin direkt radyografi ile değerlendirilmesi
}

\author{
Mehmet Ercüment Döğen'1, Ümit Yaşar Ayaz ${ }^{1}$ \\ ${ }^{1}$ Mersin Şehir Eğitim ve Araștırma Hastanesi Radyoloji ABD, Mersin, Türkiye
}

\section{$\ddot{0 ̈ z}$}

Amaç: Skleroderma olgularındaki terminal falanks değişikliklerini direkt radyografi ile ortaya koymayı amaçladık. Yöntem: Skleroderma tanısı ile izlenen ve yaş ortalaması 36.4 yıl olan (aralık, 22-48 yıl), hepsi kadın sekiz olgunun el-el bilek radyografileri akral (terminal falanks) patolojileri ve diğer el-el bileği değişiklikleri yönünden retrospektif olarak incelendi. Bulgular: Bilateral el-el bileği radyografilerinde olgularının 5'inde (\%62.5) değişik derecelerde fleksiyon kontraktürleri ve 2'sinde (\%25.0) pençe el-pençe el gelişim süreci, 6'sında (\%75.0) interkarpal, karpometakarpal, metakarpofalangeal ve interfalangeal eklemlerde değişik lokalizasyonlarda ve derecelerde artritik ve dejeneratif değișiklikler, değișik derecelerde periartiküler osteoporoz izlendi. Olguların 2'sinde (\%25.0), parmakların distalinde yumuşak doku kalsifikasyonları saptandı. Olguların 5'inde $(\% 62,5)$ değişik derecelerde terminal falanks rezorpsiyonları (akroosteoliz), erozyon görüldü. Bu periosteal rezorpsiyon ve erozyonların, taftların palmar taraflarını daha çok etkilediği saptandı. Olguların 2'sinde (\%25.0) akroosteoliz daha hafif ve sinırlı olup, 3'ünde (\%37.5) terminal falankslarda belirgin sivrileşmeler şeklinde görüldü. Sonuç: Direkt radyografi, kronik skleroderma olgularında başta akroosteoliz olmak üzere terminal falanks patolojilerini göstermede yararlı bulunmuş olup bu konuda başvurulacak ilk görüntüleme yöntemi olmalıdır.

Anahtar kelimeler: Skleroderma, akroosteoliz, radiografi, el bilek

\section{Evaluation of the chronic pathologies in terminal phalanges of scleroderma patients by plain radiography}

\begin{abstract}
Aim: We aimed to reveal the terminal phalangeal changes in scleroderma patients by plain radiography. Method: Bilateral hand-wrists radiographs of eight women with a mean age of 36.4 years (range, 22-48 years) who were on follow-up with the diagnosis of scleroderma were retrospectively evaluated for acral (terminal phalanx) pathologies and other hand-wrist changes. Results: On bilateral hand-wrist radiographs, flexion contractures with different degrees in five $(62.5 \%)$ of the all cases, claw hand and claw hand development process in two $(25.0 \%)$ of cases, arthritic and degenerative changes with varying degrees in various localizations of the intercarpal, carpometacarpal, metacarpophalangeal, interphalangeal joints, and various degrees of periarticular osteoporosis in six (75.0\%) of cases were observed.
\end{abstract}

Yazının geliş tarihi:17.09.2018

Yazın kabul tarihi:05.11.2018

Sorumlu Yazar: Mehmet Ercüment Döğen,Mersin Şehir Eğitim ve Araştırma Hastanesi Radyoloji ABD, Mersin.Tel: +90 324 2251000, E-Posta: ercumentdogen@yahoo.com 
In two (25.0\%) of the cases, soft tissue calcifications were detected in distal parts of the fingers. Terminal phalanx resorptions (acroosteolysis) and erosions with varying degrees were observed in five $(62.5 \%)$ of cases. It was detected that these periosteal resorptions and erosions were more likely to affect the palmar sides of the taft. Acroosteolysis was milder and more limited in the two $(25.0 \%)$ of the cases, and in the three $(37.5 \%)$ of cases, the terminal phalanges were seen as prominent cusps. Conclusion: Plain radiography was found to be useful in showing the terminal phalanx pathologies especially acroosteolysis, in chronic scleroderma cases and should be the first imaging method to be applied.

Key words: scleroderma, acro-osteolysis, radiography, wrist

\section{Giriş}

Çeşitli hastalıklar terminal falanksların radyografik görünümlerinde değişikliklere yol açabilir. Nadiren bazı durumlarda sağlıklı bireylerde veya idiopatik olarak, terminal falankslar normal dışı görünebilir¹. Çoğu sistemik veya lokal, konjenital veya akkiz hastalıklarda ellerdeki terminal falanks değişiklikleri direkt radyografi ile görüntülenebilir. Direkt radyografide terminal falankslarda düzgün sınırlı ve sınırları net olarak seçilebilen litik görünümler, enkondrom ${ }^{2}$ gibi benign kemik tümörlerinde, epidermoid inklüzyon kisti ${ }^{3}$ ve glomus tümörü ${ }^{4}$ gibi lezyonlarda, sarkoidozda $^{5}$ ve tüberoz sklerozda ${ }^{6}$ izlenebilir. Falanks taftını tutan ve sınırları zayıf olarak seçilebilen litik lezyonlar osteomyelitte (panaritium ossale) ve anevrizmal kemik kistinde görülebilir ${ }^{7,8}$. Terminal falanksların taban kısmını tutan ve sınırları zayıf olarak seçilebilen litik lezyonlar ise bronkojenik karsinom metastazlarında ${ }^{9}$, psöriatik artropatilerde ${ }^{10}$, fibröz displazide ${ }^{9}$ izlenebilir.

Skleroderma (sistemik skleroz) nadir görülen bir hastalıktır. Prevalans çalışmalarında şimdiye kadar bildirilen değerler milyonda 50 ile 300 arasında değişirken ülkemizde milyonda 220 olduğu bildirilmiştir.11 Skleroderma nedeni tam olarak bilinmeyen multisistem fibrozisi ve yumuşak doku kalsifikasyonu ile seyreden otoimmün bir bağ dokusu hastalığı olup, birçok ayrı organ ve sistemi etkiler.12,13 Sklerodermanın kas ve iskelet sistemi bulguları arasında distal falanksların rezorpsiyonu, akroosteoliz, kaslarda genel veya lokal atrofi ve distrofik kalsifikasyonlar, fleksiyon deformiteleri, ayaklar, kaburgalar ve mandibulada eklem yıkımına kadar değișen radyografik bulgular saylabilir ${ }^{14}$. Akroosteoliz terminal falankslarda kemik rezorbsiyonuna bağlı olarak incelme ve șekil değișikliği (bazen sivrileşme, bazen küntleșme) ile karakterize litik görünümlerle ilgili genel bir tanımlamadır. Akroosteoliz, birçok sistemik hastalıkta ellerdeki terminal falanksların taft değişiklikleri primer patolojiyi düşündürecek veya mevcut tanıyı destekleyecek görünümde olabilir ${ }^{12}$. Manyetik rezonans (MR) görüntülemede ise kontrast öncesi ve sonrası imajlarda, fasiyalarda kalınlaşma, eklem sinoviti, tenosinovit, perifasyal kontrast tutulumu, miyozit, kemik iliği tutulumu ve subkutan septal kalınlaşma görülmüștür. ${ }^{15}$

$\mathrm{Bu}$ çalışmada Skleroderma hastalığının el ve el bileğinde yaptığı tutulumların ve bu tutlumların hafif ve ileri formlarının radyografi ile gösterilmesi hedeflenmiștir. Ayrıca bașta akroosteoliz olmak üzere fleksiyon kontraktürleri, ciltaltı kalsifikasyonlar ve pençe el deformitesi gibi bu hastalıkla görülen bulguların da sıklığının saptanması amaçlanmıştır.

\section{Yöntem}

Tanımlayıcı tipte çalışmamıza, Mersin Şehir Eğitim ve Araştırma Hastanesi Radyoloji Kliniği arşivinde bulunan, American Rheumatism Association (ARA) kriterlerine $^{16}$ göre 2001-2013 ylları arasında skleroderma tanısı almış veya bu kriterlere göre klinik olarak takip edilmiş, toplam 17 olgunun sekizi dâhil edildi. Dokuz olgu ise erken dönem yeni tanılı oldukları 
veya klinik verileri yeterli olmadığı için çalışmadan çıkarıldı.

Dahil edilen ve hepsi bir yıldan fazla bir süre önce tanı almıș kronik skleroderma olgularının el-el bilek radyografileri, akral (terminal falanks) patolojileri ve diğer el-el bileği değişiklikleri yönünden retrospektif olarak incelendi. Çalışmamız hastalardan onam formu alınarak, etik ilkelere ve Dünya Sağlık Örgütünün Helsinki Bildirisine uygun olarak gerçekleştirildi. Çalışmamız Mersin Üniversitesi Klinik Araştırmalar Etik Kurulu'ndan 06.09.2018 tarihli 78017789/050.01.04/ 830075 sayll kurul kararı ile etik kurul onayı almıștır.

Veriler bilgisayar ortamına girildi. Verinin analizinde sayı, yüzde, ortalama gibi tanımlayıcı istatistikler kullanıldı.

\section{Bulgular}

Çalışmaya dahil edilen olguların hastalık süresi ortalaması 10.2 yıl (aralık, 714 yll), hepsi kadın $(\mathrm{n}=8 / 8)$ ve yaş ortalaması 36.4 yıl (aralık, 22-48 yıl) olarak belirlendi. Bilateral el-el bileği radyografilerinde, olguların 5'inde (\%62.5) değişik derecelerde fleksiyon kontraktürleri ve 2 'sinde (\%25.0) pençe el-pençe el gelişim süreci (Resim 1) 6'sinda (\%75.0) interkarpal, karpometakarpal, metakarpofalangeal ve interfalangeal eklemlerde değişik lokalizasyonlarda ve derecelerde artritik ve dejeneratif değişiklikler, değişik derecelerde periartiküler osteoporoz izlendi.

$$
\text { Olguların 2'sinde (\%25.0), }
$$
parmakların distalinde yumuşak doku kalsifikasyonları saptandı (Resim 2). Olguların 5'inde (\%62.5) değişik derecelerde terminal falanks rezorpsiyonları (akroosteoliz), erozyon görüldü. $\mathrm{Bu}$ periosteal rezorpsiyon ve erozyonların, taftların palmar taraflarını daha çok etkilediği saptandı.

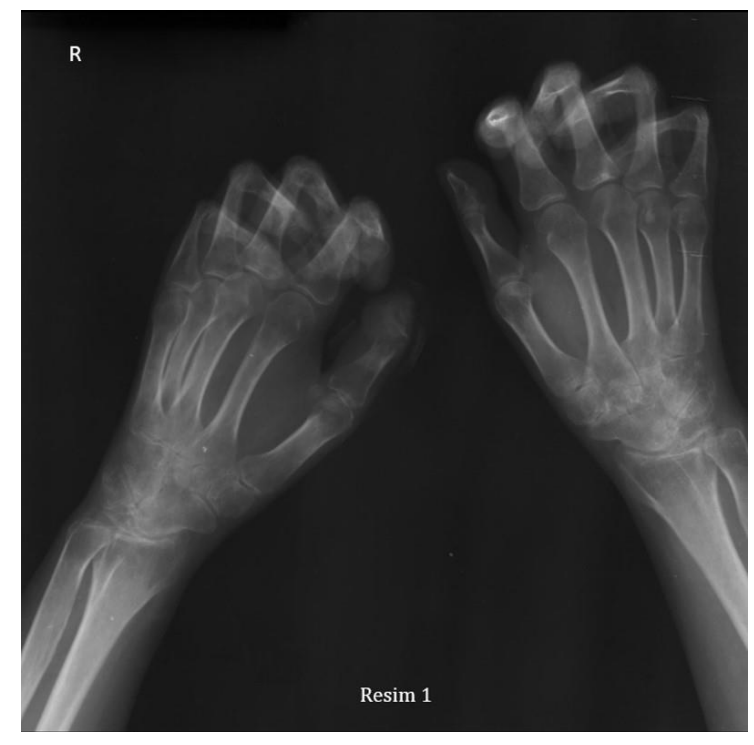

Resim 1: 10 yıldır skleroderma tanısı ile izlenen 33 yaşındaki kadın olguda terminal falankslarda belirgin akroosteoliz, radiokarpal, radioulnar, interkarpal, metakarpofalangeal eklemlerde daha net seçilebilen periartiküler osteoporoz ve fleksiyon kontraktürlerine bağlı olarak her iki elde pençe görünümü izlenmektedir.

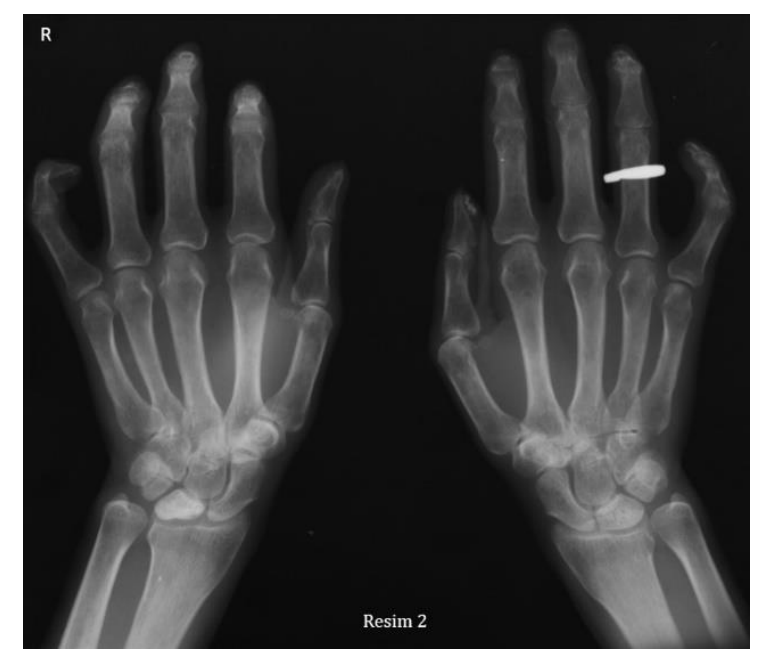

Resim 2: Skleroderma tanısı ile izlenen 30 yaşındaki kadın olguda bilateral el-el bileği radyografisinde terminal falankslarda belirgin akroosteoliz görünümüne ilave olarak 1. parmakların distal falanksları komşuluğunda solda daha belirgin olmak üzere punktat radyoopasiteler şeklinde yumuşak doku kalsifikasyonları izlenmektedir. Her iki el 4 . ve 5 . parmaklarda daha belirgin olmak üzere fleksiyon kontraksiyonları gelişmeye başlamış. 
Olguların 2'sinde (\%25.0) akroosteoliz daha hafif ve sinırlı olup (Resim 3), olguların 3'ünde ise (\%37.5) terminal falankslarda belirgin sivrileşmeler şeklinde görüldü.



Resim 3: 10 yıldır skleroderma tanısı ile takip edilen 48 yaşındaki kadın olgunun bilateral el-el bileği radyografisinde sağ el 2 . parmak terminal falanksında belirgin, diğer kesimler yer yer ve daha hafif, sinırl düzeyde terminal falanks rezorpsiyonları görülmektedir. Belirgin periartiküler osteoporoz izlenmemektedir.

\section{Tartışma}

Akroosteoliz akkiz veya ailesel olabilir. Akkiz akroosteoliz nedenleri arasında, özellikle skleroderma ve dermatomyozit olmak üzere kollajen doku hastalıkları ${ }^{14}$, Sjögren sendromu ${ }^{12}$, hiperparatiroidizm ve renal osteodistrofi ${ }^{17}$, psöriatik artritler ${ }^{18}$, tromboanjitis obliterans ${ }^{19}$, diabetik gangren ${ }^{17}$, donmalar, elektrik ve radyasyon hasar1 17,18 , LeschNyhan Sendromu17-19, yanıklar ${ }^{19}$, Raynaud hastalığ ${ }^{19}$, nörotrofik hastalıklar, epidermolizis bülloza, polivinilklorid (PVC) maruziyeti 18,19 , Kaposi sarkomu, Rothmund Sendromu ${ }^{17-19}$ sayılabilir. Bu patolojilerde izlenen akroosteolizde periost reaksiyonu görülmez.17,19 Kollajen vasküler doku hastalıklarından özellikle skleroderma ve dermatomyozitte, hiperparatiroidizmde, epidermolizis büllozada, konjenital ağrı duyarsızlı̆̆ında ilave yumuşak doku kalsifikasyonları izlemek olasıdır. ${ }^{20}$ Ailesel olarak akroosteoliz izlenen ve familyal idiopatik akroosteoliz olarak da isimlendirilen Hajdu-Cheney Sendromunda çeșitli muskuloskeletal anormallikler izlenebilir ve el ve ayak parmaklarının terminal falankslarında akroosteoliz ve daha proksimal falankslarında rezorptif değişiklikler görülür. ${ }^{21}$

Sklerodermanın el ve parmak tutulumunda sklerodaktili görülür. ${ }^{22}$. Ciltte atrofi, parmak uçlarındaki yumuşak dokunun rezorpsiyonu ve yumuşak doku kalsifikasyonları nedeni ile parmaklar sertleşir; ilave fleksiyon kontraktürleri ile eller pençe görünümü alabilir.14. Terminal falanks taftlarının, palmar taraftan başlayan ve proksimale doğru ilerleyen rezorpsiyonu ile akroosteoliz adı verilen kalem şeklinde incelme ve sivrileșmeler görülür. ${ }^{22}$ Skleroderma artritinde terminal falanksların palmar taraflarının rezorpsiyonu en sik bulgudur. ${ }^{19}$ Birinci karpometakarpal eklemler, metakarpofalangeal eklemler, distal ve proksimal interfalangial eklemler tutulabilir. Karpal kemiklerde (trapezium), distal radius ve ulnada kemik erozyonları görülebilir. ${ }^{20}$ Geç dönemlerde eklem aralıklarında daralmalar izlenebilir.,20,21 Sklerodermada, şiddeti hastalığın süresine ve sinoviyal enflamasyonun derecesine bağlı olarak değișen periartiküler (jukstaartiküler veya subkondral) demineralizasyon (osteoporoz) görülebilir.21,22 $\mathrm{Bu}$ rezorpsiyonların taftların palmar tarafını daha çok etkilediği görülmüştür. Johnstone ve ark. $^{22} 101$ sklerodermalı hastada akroosteoliz sinıflandırması yapmıș bunların 68'inde tip 1-2 (normal ve hafif derecede) akroosteoliz, 38 hastada tip 3-4 (orta ve ağır) akroosteoliz saptamışlardır. Bizim çalışmamızdaki olgularda, \%37,5'i belirgin sivrileşmeler şeklinde olmak üzere $\% 62,5$ oranında akroosteoliz tespit ettik. Yumuşak doku kalsifikasyonu, çalışmamızda $\% 25$ oranında görülmüş olup Basset $L W$ ve ark. ${ }^{14} 55$ hasta ile yaptıkları çalışmada elde ettikleri frekans $(14 / 55, \% 25,5)$ ile uyumludur. Çalışmamızda değişik 
derecelerde fleksiyon deformitelerini \%62,5 oranında, pençe el-pençe el gelişim sürecini $\% 25$ oranında ve dejeneratif değişiklikler ile periartriküler osteoporozu \%75 oranında tespit ettik. Bu oranlar, Basset LW ve ark. ${ }^{14}$ tespit ettikleri oranlar ile benzerlik göstermektedir.

Çalışmamızda bazı kısıtlılıklar mevcuttur. Hasta sayımız sinırlıdır. Bununla birlikte, direkt radyografiler mevcut olgularda patolojileri göstermede yeterli bulundu. Direkt radyografi bulgularının MR görüntüleme gibi ileri görüntüleme yöntemleri ile korele edilmemesi de bir diğer kısıtlılıktı. MR bu olgularda kemik iliği, yumuşak doku ödemini gösterebilirdi. ${ }^{15}$ Gelecekteki çalışmalarda direkt radyografi ve MR bulgularinın korele edilmesi ilave bilgiler sağlayacaktır.

Sonuç olarak, çoğunluğu sistemik ve akkiz olmak üzere çeşitli patolojilerde el parmaklarının terminal falankslarında direkt radyografi ile tespit edilebilecek kemik değişiklikleri ve ilave yumuşak doku anormallikleri, kalsifikasyonlar görülebilir. Vücudun diğer bölgelerindeki radyolojik ve klinik bulgularla beraber değerlendirildiğinde, terminal falankslardaki görünümlerin çoğu, patolojinin aydınlatılmasında veya spesifiye edilmesinde yardımcl rol oynar. Olgularımızda akroosteoliz ağırlıklı terminal falanks patolojileri başta olmak üzere tüm kemik yapı değiş̧iklikleri ve yumuşak doku kalsifikasyonları direkt radyografi ile gösterilebilmiş ve primer tanılar bu görünümlerle desteklenmiştir. Direkt radyografi kronik skleroderma olgularında terminal falanks patolojilerini göstermede yararlı bulunmuş olup bu konuda başvurulacak ilk görüntüleme yöntemi olmalıdır.

\section{Çıkar çatışması}

Çıkar çatışması yoktur.

\section{Teşekkür bölümü}

Prof. Dr. Baki Hekimoğlu'ya katkılarından dolayı teșekkür ederiz.

\section{Kaynaklar}

1. Burgener FA, Kormano M. Differential diagnosis in conventional radiology. 2nd ed. New York: Thieme Medical Publishers Inc. 1991;87,270,274-281.

2. Lu H, Chen $Q$, Yang $H$, Shen $H$, Liu Y. Enchondroma in the distal phalanx of the finger An observational study of 34 cases in a single institution. Medicine (Baltimore). 2016; 95(38):4966.

3. Zadek I, Cohen HG. Epidermoid cyst of the terminal phalanx of a finger; with a review of the literature. Am J Surg. 1953;85(6):771-774.

4. Van Geertruyden J, Lorea P, Goldschmidt D, de Fontaine S, Schuind F, Kinnen L, et al. Glo-mus tumours of the hand. A retrospective study of 51 cases. J Hand Surg Br 1996;21:257-260.

5. Zisman DA, Shorr AF, Lynch JP 3rd. Sarcoidosis involving the musculoskeletal system. Semin Respir Crit Care Med 2002;23(6):555-70.

6. Holt JF, Dickerson WW. The osseous lesions of tuberous sclerosis. Radiology 1952;58(1):1-8.

7. McKay P, Formby P, Dickens, JF, Gibson M. Osteomyelitis and septic arthritis of the hand and wrist. Current Orthopaedic Practice 2010;21: 542-550

8. Leeson MC, Lowry L, McCue RW. Aneurysmal bone cyst of the distal thumb phalanx. A ca-se report and review of the literature. Orthopedics 1988;11(4):601-604.

9. Flynn CJ, Danjoux C, Wong J, Christakis M, Rubenstein J, Yee A, Yip D, Chow E. Two cases of acrometastasis to the hands and review of the literature. Curr Oncol 2008;15(5):51-58.

10. Ory PA, Gladman DD, Mease PJ. Psoriatic arthritis and imaging. Ann Rheum Dis 2005;64:55-57.

11. Pamuk O.N. Sistemik Sklerozun Epidemiyolojisi. Turkiye Klinikleri J Rheumatol-Special Topics 2015;8(2):7-13. 
12. Botou A, Bangeas A, Alexiou I, Sakkas L. Acro-osteolysis. Clin Rheumatol 2017;36(1):9-14.

13. Demir K, Acartürk G. Skleroderma ve Özofagus. Turkiye Klinikleri J Gen SurgSpecial To-pics 2012;5(3):112-115.

14. Bassett LW, Blocka KL, Furst DE, Clements PJ, Gold RH. Skeletal findings in progressive systemic sclerosis (scleroderma) American Journal of Rentgenology 1981;136:1121-1126.

15. Schanz S, Henes J, Ulmer A, Kötter I, Fierlbeck G, Claussen CD, Horger M. Magnetic reso-nance imaging findings in patients with systemic scleroderma and musculoskeletal symptoms. Radiol 2013;23(1):212-221.

16. Preliminary criteria for the classification of systemic sclerosis (scleroderma). Subcom-mittee for scleroderma criteria of the American Rheumatism Association Diagnostic and Therapeutic Criteria Committee. Arthritis Rheum 1980 ;23(5):581-590.

17. Ferreira IR, Domingues VS. Acroosteolysis. Lancet 2012: 380, 916.

18. Greenspan A. Orthopedic radiology. 3rd ed. Philadelphia: Lippincott Williams and Wilkins, 2000;480-483.

19. Dahnert W. Radiology Review Manual. 4th ed. Baltimore: Williams and Wilkins, 1999;16,60,141,711.

20. Avouac J, Guerini H, Wipff J et-al. Radiological hand involvement in systemic sclerosis. Ann Rheum Dis. 2006;65(8):10881092.

21. Tuncel E. Klinik Radyoloji. 1st ed. Bursa:Güneş ve Nobel Tip Kitapevleri, 1994;491.

22. Johnstone EM1, Hutchinson CE, Vail A, Chevance A, Herrick AL. Acro-osteolysis in syste-mic sclerosis is associated with digital ischaemia and severe calcinosis. Rheumatology (Oxford) 2012;51(12):22342238. 